\title{
Case Study on Risk Evaluation of Silver Nanoparticle Exposure from Antibacterial Sprays Containing Silver Nanoparticles
}

\author{
Ellen Kim, ${ }^{1}$ Ji Hyun Lee, ${ }^{1}$ Jin Kwon Kim, ${ }^{1}$ Gun Ho Lee, ${ }^{2}$ Kangho Ahn, \\ Jung Duck Park, ${ }^{3}$ and II Je Yu ${ }^{1}$ \\ ${ }^{1}$ Institute of Nanoproduct Safety Research, Hoseo University, Asan 31499, Republic of Korea \\ ${ }^{2}$ Department of Mechanics, Hanyang University, Ansan 15588, Republic of Korea \\ ${ }^{3}$ College of Medicine, Chung-Ang University, Seoul 06911, Republic of Korea \\ Correspondence should be addressed to Il Je Yu; u1670916@chollian.net
}

Received 7 June 2015; Accepted 11 October 2015

Academic Editor: Simeon Agathopoulos

Copyright (C) 2015 Ellen Kim et al. This is an open access article distributed under the Creative Commons Attribution License, which permits unrestricted use, distribution, and reproduction in any medium, provided the original work is properly cited.

\begin{abstract}
This study evaluated the risk of silver nanoparticle (AgNP) exposure from antibacterial sprays containing AgNPs. Using an exposure simulation chamber as the setting for the experiment, various instruments, including a scanning mobility particle sizer (SMPS), condensation particle counter (CPC), dust monitor, and mixed cellulose esters (MCE) filters, are connected to the chamber to measure the exposure levels of AgNPs when using the sprays. To assess potential risks to consumers, margin of exposure (MOE) approach was used to assess risk in which a calculated MOE was compared with a target MOE. When evaluating the risk of antibacterial sprays to inhalation exposure using the MOE, spraying a whole can and spraying an air conditioner both resulted in a high-risk concern level with a MOE ranging from 59 to 146 that was much lower than the no-risk concern level of 1000 , while some spray showed a MOE 2049 with no-risk concern level. The dermal exposure levels with a single layer of clothing were estimated at $2-50 \mu \mathrm{g} / \mathrm{kg} /$ day with a MOE ranging from 20,000 to 500,000. Therefore, the current results showed the possibility of high-risk inhalation exposure to AgNPs released when using antibacterial sprays.
\end{abstract}

\section{Introduction}

The safety of products containing nanomaterials remains an obstacle to the commercialization of nanotechnologies. An international standard (ISO TS 13830) "Guidance on the voluntary labeling for consumer products containing manufactured nano-objects" has been developed in ISO TC 229 (nanotechnologies) to allow informed choices when purchasing and for the use of consumers [1]. While the initial labeling standard suggested the inclusion of nanoobject release elements if manufactured nanoobjects are released during the product life-cycle, this proposal is currently unfeasible due to the lack of technology for detecting the release of nanoobjects during the product life-cycle. Thus, the present labeling standard only lists the manufactured nanoobjects contained in a product.

Another international collaborative effort to standardize the measurement of nanoparticles released from a product is the Nanorelease Consumer Products Program organized by ILSI (International Life Science Institute). The program has 3 phases: (1) nanomaterial selection, (2) method evaluation, and (3) interlaboratory studies with an interlaboratory testing group [2]. After reviewing 24 nanomaterials, MWCNTs in polymers were determined as the top-priority nanomaterials. Various measurement methods and exposure/release scenarios were reviewed during different workshops. Therefore, several interlaboratory studies are now underway for method development and refinement [2].

Tracking the expanded application of nanomaterials, the consumer products inventory created by the project on emerging nanotechnologies [3] currently lists 1,628 products, where AgNPs are included in 383 products. In particular, the antimicrobial function of AgNPs has resulted in their widespread use in sprays, bedding, washers, water purification, wound dressings, toothpaste, shampoo and rinse, nipples and nursing bottles, fabrics, deodorants, filters, kitchen 
TABLE 1: Inhalation exposure to $\operatorname{AgNPs}\left(\mu \mathrm{g} / \mathrm{m}^{3}\right)$.

\begin{tabular}{|c|c|c|c|c|c|c|}
\hline Company & $N^{(\mathrm{a})}$ & $\begin{array}{c}\text { Pump flow }{ }^{(b)} \\
\text { (L/min) }\end{array}$ & Sampling time $(\min )$ & $\begin{array}{l}\text { Ag conc } \\
\left(\mu \mathrm{g} / \mathrm{m}^{3}\right)\end{array}$ & $\mathrm{MOE}$ & Average MOE \\
\hline \multirow{3}{*}{ Company $A^{(d)}$} & 8 & $2.16 \pm 0.09$ & 25 & $0.049 \pm 0.004$ & 2714 & \multirow{3}{*}{$2049 \pm 577$} \\
\hline & 5 & $2.07 \pm 0.03$ & 25 & $0.076 \pm 0.015$ & 1750 & \\
\hline & 6 & $2.07 \pm 0.03$ & 25 & $0.079 \pm 0.005$ & 1684 & \\
\hline \multirow{3}{*}{ Company $\mathrm{B}^{(\mathrm{d})}$} & 8 & $2.07 \pm 0.03$ & 25 & $0.887 \pm 0.371$ & 149 & \multirow{3}{*}{$146 \pm 12$} \\
\hline & 6 & $2.07 \pm 0.03$ & 25 & $1.005 \pm 0.414$ & 132 & \\
\hline & 6 & $2.07 \pm 0.03$ & 25 & $0.849 \pm 0.373$ & 156 & \\
\hline Company B.1 $1^{(\mathrm{c})}$ & 7 & $2.17 \pm 0.10$ & 25 & $2.266 \pm 0.197$ & 59 & 59 \\
\hline
\end{tabular}

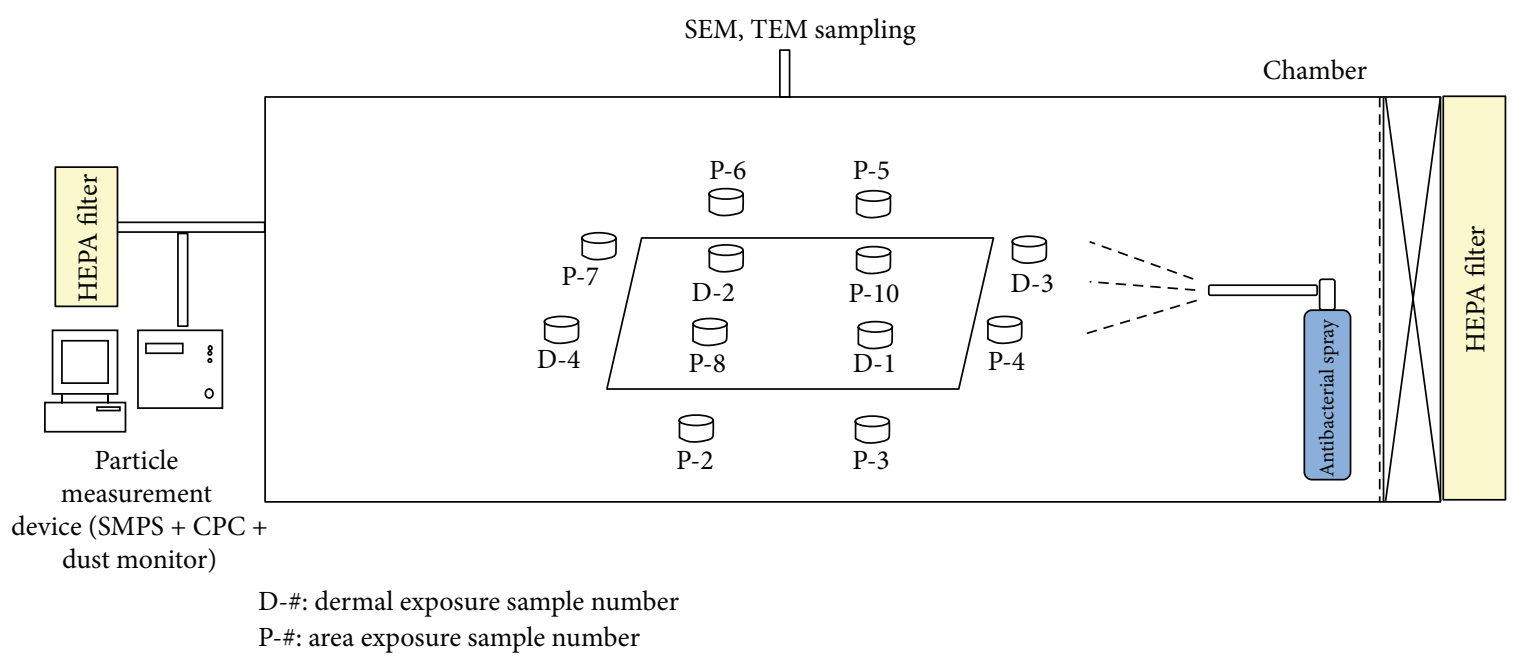

FIGURE 1: Schematic diagram of antibacterial spray exposure assessment system.

utensils, toys, photocatalysts, and humidifiers. Thus, the likelihood of consumers being exposed to AgNPs is increasing.

Antibacterial sprays are used on a wide variety of surfaces, including sinks, toilets, home appliances, air conditioners, tables, and chairs. Thus, the AgNPs in antibacterial sprays can be found in the air or on surfaces, meaning that consumers can be exposed through inhalation or via the skin. In addition, AgNPs sprayed on toilets, sinks, and bathtubs can enter the water system and eventually affect living organisms in the aquatic environment [4]. While antibacterial sprays are regulated by the FIFRA (Federal Insecticide, Fungicide Rodenticide Act) in the USA and Biocide act in the EU, many other parts of the world have no specific regulations.

Accordingly, this report simulates the use of AgNP containing sprays in a chamber system to assess AgNP exposure through inhalation and dermal routes. The human health effects of inhalation and dermal exposure to AgNPs from the use of sprays are also evaluated.

\section{Materials and Methods}

2.1. Antibacterial Sprays. Two kinds of antibacterial spray containing AgNPs were used, where the ingredients listed on the cans included fragrance, AgNPs, and incense. The spray cans from Company A and Company B contained $0.08 \mu \mathrm{g} / \mathrm{g}$ and $1.1 \mu \mathrm{g} / \mathrm{g}$ of $(\mathrm{Ag})$, respectively. These average amounts of $\mathrm{Ag}$ are listed in Table 1.

2.2. Exposure Simulation Chamber and Real-Time Aerosol Monitoring. The dimensions of the exposure simulation chamber were $1,800 \mathrm{~mm} \times 700 \mathrm{~mm} \times 700 \mathrm{~mm}$ and it was made of acrylic, as shown in Figure 1. To facilitate various measurements, such as the AgNP particle number, size distribution, and mass concentration, a SMPS, CPC, dust monitor, and MCE filters were all connected to the exposure simulation chamber. The SMPS combining a differential mobility analyzer (DMA, 4220, HCT Co., Ltd., Icheon, Korea) and CPC (4312, HCT Co., Ltd.) was used to monitor the particle size distribution with an electrical mobility diameter ranging from 7.37 to $289.03 \mathrm{~nm}$, while the dust monitor (Model 1.109, Grimm) was used to observe the particle size distribution with a diameter ranging from 0.25 to $32 \mu \mathrm{m}$. Another CPC (3775, TSI Co., Ltd., $1-10^{7}$ particles $/ \mathrm{cm}^{3}$, detection range) was also used to monitor the number concentration, while the MCE filters were used in adjacent and nearby areas for personal and area sampling. The antibacterial spray was 
applied to the air conditioner for 15 seconds, and, for the next 10 minutes including the 15 seconds of spraying, the air conditioner was not used. The air conditioner was then turned on for 50 minutes. The whole experiment took one hour and was repeated three times. Each repeated experiment is done in a clean simulation chamber, where the CPC observed no particles.

2.3. Air Sampling. Air samples were taken by drawing air through MCE filters in sampling cassettes $(0.45 \mu \mathrm{m}, 37 \mathrm{~mm}$ support pad included) obtained from SKC Inc. The total suspended particulate (TSP) was then measured, followed by a metal component analysis of the TSP and a metal component analysis. Area samples were collected from the chamber floor and $30 \mathrm{~cm}$ above using MSA (Escort Elf pump, Zefon International Inc., USA) sampling pumps at a flow rate of $2.07-2.17 \mathrm{~L} / \mathrm{min}$. The antibacterial spray was applied to the air conditioner for 15 seconds, and, for the next 10 minutes including the 15 seconds of spraying, the air conditioner was not used. The air conditioner was then turned on for 15 minutes. The whole experiment took 25 minutes and was repeated three times. Each repeated experiment is done in a clean simulation chamber, where the CPC observed no particles.

2.4. Dermal Exposure Estimation. To estimate the dermal exposure, MCE filter cassettes were placed in the chamber for passive sampling with no pump flow. The filters were then analyzed for their Ag concentrations, as described in Section 2.5, which were expressed as $\mu \mathrm{g} / \mathrm{cm}^{2} / \mathrm{min}$.

2.5. Metal Analysis. After wet digestion, the filter concentrations of residual metals were analyzed using an atomic absorption spectrometer (AAS) equipped with a Zeeman graphite furnace (GF, pinAAcle 900T, Perkin Elmer, Waltham, MA) based on National Institute for Occupational Safety and Health (NIOSH) Manual method 7302 [7]. The filters were digested in a microwave (CEM MARS Xpress, Matthews, NC) for $60 \mathrm{~min}$ at $120^{\circ} \mathrm{C}$ in the presence of nitric acid and perchloric acid at a ratio of $4: 1$. Thereafter, the samples were allowed to cool and analyzed by AAS/GF. The LOD and LOQ for the AAS Ag analysis were 0.098 and $0.323 \mathrm{ppb}$, respectively.

2.6. Transmission Electron Microscopy (TEM). TEM, including an energy dispersive X-ray analyzer (EDS), was used to measure the nanoparticles based on NIOSH analytical method 7402 [8]. The nanoparticles on the filter were mounted on a TEM grid (copper grid) and visualized under a field emission transmission electron microscope (FE-TEM, JEM2100F, JEOL, Japan). The particles were measured at a magnification of 100000 and the nanoparticles analyzed using an energy dispersive X-ray spectrometer (EDS, TM200, Oxford, UK) at an accelerating voltage of $75 \mathrm{kV}$.

2.7. Risk Analysis. A MOE approach was used to assess the risk, where the calculated MOE was compared to a target MOE. Thus, when the calculated MOE is less than the target MOE, this represents a risk concern level, whereas when the calculated MOE is greater than the target MOE, this represents a no-risk concern level. In this study, the target MOE was set at 1000 . The $\mathrm{MOE}_{\text {calc }}=$ the $\mathrm{POD} /$ dose (NOAEL)/exposure concentration, where the POD is the toxicological point of departure according to the estimated dose to which humans will be exposed and the NOAEL is the no-observed-adverse-effect-level. In this study, the POD was $133 \mu \mathrm{g} / \mathrm{m}^{3}$ based on the NOAEL from a laboratory AgNP subchronic animal inhalation study [5]. In a previous acute dermal toxicity study based on OECD Test Guide 402, AgNPs did not induce any abnormal signs or death up to $2,000 \mathrm{mg} / \mathrm{kg}$ and no abnormal gross findings were reported for any of the treated groups at necropsy [9]. In another 28-day repeated dermal toxicity test based on OECD Test Guideline 410, a NOAEL of $1,000 \mathrm{mg} / \mathrm{kg}$ was obtained. Thus, to estimate the AgNP dermal risk, this study used a NOAEL of $1,000 \mathrm{mg} / \mathrm{kg}$. To calculate the total exposure per day, the maximum exposure per day was set at four hours as worstcase scenario based on our simulated use scenario (15 sec spray, 10 min drying, and 10 min use). The dermal absorption factor was set at 0.01 [10], the body surface area for an adult was set at $1.5 \mathrm{~m}^{2}$, and the body weight was set at $70 \mathrm{~kg}$ [11]. A $50 \%$ reduction was assumed in the case of a single layer of clothing based on the US EPA surrogate PHED surrogate exposure guide [12]. Thus, the daily dermal exposure was as follows:

Dermal exposure/kg/day

$=($ Dermal exposure concentration $\times$ surface area

$\times$ work duration) $\times \frac{\text { dermal absorption factor }}{\text { body weight }}$.

\section{Results}

3.1. Inhalation Exposure to AgNPs from Spraying. The Ag concentrations were measured after using the sprays from Company A and Company B (15 seconds of spraying, 25 minutes total sampling time) and Company B.1 (10 minutes of spraying, 25 minutes total sampling time). The Ag concentrations for the sprays from Company A, Company B, and Company B.1 were 0.066 $\pm 0.016,0.911 \pm 0.370$, and $2.27 \pm 0.2 \mu \mathrm{g} / \mathrm{m}^{3}$, respectively. The MOEs for the sprays from Company B and Company B.1 were 146 and 59, respectively, indicating a risk concern level. However, the MOE for the spray from Company A was 2049, indicating a no-risk concern level (Table 1).

3.2. Particle Size Distribution and Number Concentration during Use of Spray. The particle number concentration for the spray from Company A ranged from 5,901.6 to 365,500 particle $/ \mathrm{cm}^{3}$ when measured using the CPC and from 1,703.3 to $9,521.8$ particle $/ \mathrm{cm}^{3}$ when measured using the dust monitor after the $25 \mathrm{~min}$ simulated exposure, and the concentration gradually decreased up to $100 \mathrm{~min}$ (Figure 2(a)). The particle size distribution ranged from $10 \mathrm{~nm}$ to $200 \mathrm{~nm}$, showing peak at $30 \mathrm{~nm}$, when measured using the SMPS 


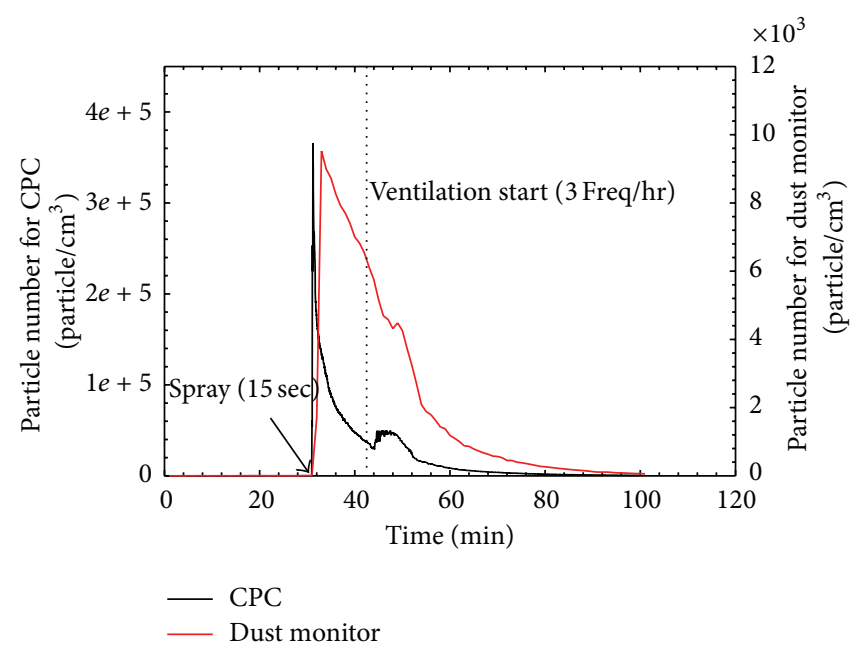

(a)

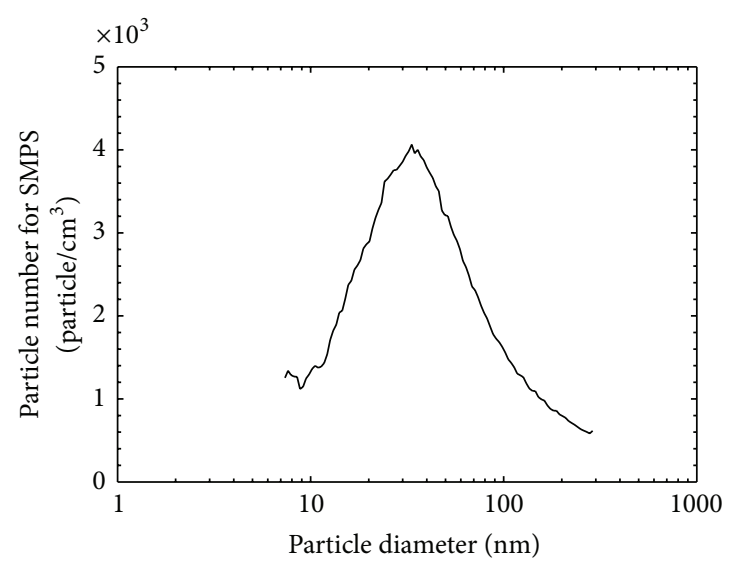

(b)

Figure 2: Particle number concentrations and particle size distribution. (a) Particle number concentrations for spray from Company A measured using dust monitor and CPC and (b) particle size distribution for spray from Company B measured using SMPS.

(Figure 2(b)). Meanwhile, the particle number concentration for the spray from Company B ranged from 23,952.1 to 582,100 particle $/ \mathrm{cm}^{3}$ when measured using the CPC and from $5,152.8$ to $9,843.3$ particle $/ \mathrm{cm}^{3}$ when measured using the dust monitor after the 25 min simulated exposure, and the concentration gradually decreased up to $100 \mathrm{~min}$ (Figure 3(a)). The particle size distribution ranged from $10 \mathrm{~nm}$ to $200 \mathrm{~nm}$, showing a peak at $40 \mathrm{~nm}$, when measured using the SMPS (Figure 3(b)). Finally, the particle number concentration for the spray from Company B.1 ranged from 16,331.8 to $1,908,000$ particle $/ \mathrm{cm}^{3}$ when measured using the CPC after the 25 min simulated exposure, and the concentration gradually decreased up to $100 \mathrm{~min}$ (Figure 3(c)). The particle size distribution ranged from $10 \mathrm{~nm}$ to $200 \mathrm{~nm}$, showing a peak at $40 \mathrm{~nm}$, when measured using the SMPS (Figure 3(d)). Figure 4(a) shows the particle size distribution difference when using the spray from Company B.1: 10-20 nm peak after 15 seconds of spraying, $40 \mathrm{~nm}$ after 10 minutes of spraying, and $80 \mathrm{~nm}$ after 20-30 minutes of spraying. Figure 4(b) shows the particle size distribution when using the spray from Company B: $30 \mathrm{~nm}$ peak after 15 seconds of spraying, $60 \mathrm{~nm}$ at 10 minutes after spraying, and $80 \mathrm{~nm}$ at 20-30 minutes after spraying. Figure 4(c) shows the particle size distribution when using the spray from Company A: $30 \mathrm{~nm}$ peak after 15 seconds of spraying, $50 \mathrm{~nm}$ at 10 minutes after spraying, and $50 \mathrm{~nm}$ at 20-30 minutes after spraying. The particles captured in the MCE filter analyzed by TEM-EDS showed dispersed AgNP composed of Ag with some $\mathrm{Zn}$ and $\mathrm{Si}$ component (Figure 5), indicating that the antibacterial Ag spray contained other particles.

3.3. Dermal Exposure to AgNPs from Spraying. The dermal exposure to AgNPs when spraying the whole can and for the 25 min simulation (15 seconds of spraying; 19 minutes of drying; 15 minutes of ventilation) for the spray from Company B was $0.194 \pm 0.072$ and $0.006 \pm 0.0005 \mu \mathrm{g} / \mathrm{cm}^{2} / \mathrm{min}$, respectively. The MOE when using the whole spray can from Company B was 10,000 for no clothing and 20,000 for a single layer of clothing. For the $25 \mathrm{~min}$ simulation, the MOE for the spray from Company B was 125,000 for no clothing and 250,000 for a single layer of clothing, while the MOE for the spray from Company A was 333,333 for no clothing and 500,000 for a single layer of clothing (Table 2). Thus, none of the AgNP spray scenarios represented a risk concern level for dermal exposure.

\section{Discussion}

Knowing about the safety of products containing nanomaterials is an important step for the sustainable growth of nanotechnologies, especially since their usages are gradually increasing. Several products containing nanomaterials have already been withdrawn from the market due to consumer concerns over safety and health risks related to the release of nanomaterials from products containing nanomaterials.

The release of AgNPs from consumer products, such as sock fabrics or home furnishings, has already been evaluated $[13,14]$. As a result, the release of nano-Ag ranged up to 45 micrograms per product and the size fractions were both larger and smaller than $100 \mathrm{~nm}$. After reviewing 54 studies of nanomaterial release from solid nanocomposites, the frequent releases were (1) only matrix particles, (2) matrix particles with partially or fully embedded nanomaterials, (3) nanomaterials entirely dissociated from the matrix, and (4) dissolved ionic forms of the added nanomaterials [15].

In 2010, the US EPA published a case study of nanoscale Ag in disinfectant sprays and indicated that the potential for human and biotic nano-Ag toxicity depended on the level 
TABLE 2: Dermal exposure to Ag concentrations.

\begin{tabular}{|c|c|c|c|c|c|c|c|}
\hline $\begin{array}{l}\text { Company } \\
(\text { Mean } \pm \text { SD) }\end{array}$ & $N^{(\mathrm{a})}$ & $\begin{array}{c}\text { Sampling } \\
\text { Time (min) }\end{array}$ & $\begin{array}{c}\text { Ag conc. } \\
\left(\mu \mathrm{g} / \mathrm{cm}^{2} / \mathrm{min}\right)\end{array}$ & No clothing ( $\mu \mathrm{g} / \mathrm{kg} /$ day) & MOE & Single layer clothing ( $\mu \mathrm{g} / \mathrm{kg} /$ day $)$ & MOE \\
\hline \multirow{3}{*}{ Company $A^{(c)}$} & 4 & 25 & $0.006 \pm 0.000$ & \multirow{3}{*}{3} & \multirow{3}{*}{333,333} & \multirow{3}{*}{2} & \multirow{3}{*}{500,000} \\
\hline & 4 & 25 & $0.006 \pm 0.000$ & & & & \\
\hline & 4 & 25 & $0.005 \pm 0.000$ & & & & \\
\hline \multirow{2}{*}{ Company $\mathrm{B}^{(\mathrm{c})}$} & 3 & 25 & $0.013 \pm 0.001$ & \multirow{2}{*}{8} & \multirow{2}{*}{125,000} & \multirow{2}{*}{4} & \multirow{2}{*}{250,000} \\
\hline & 4 & 25 & $0.015 \pm 0.002$ & & & & \\
\hline Company B. $1^{(\mathrm{b})}$ & 4 & 25 & $0.194 \pm 0.072$ & 100 & 10,000 & 50 & 20,000 \\
\hline
\end{tabular}

${ }^{(\mathrm{a})}$ Number of sample; ${ }^{(\mathrm{b})}$ spraying of whole can $(10 \mathrm{~min}) ;{ }^{\left({ }^{(c)}\right.}$ spraying of air conditioner (15 sec spraying, 10 min drying, 15 min use). MOE = NOAEL/exposure concentration; NOAEL $=2000 \mathrm{mg} / \mathrm{kg}[6]$.

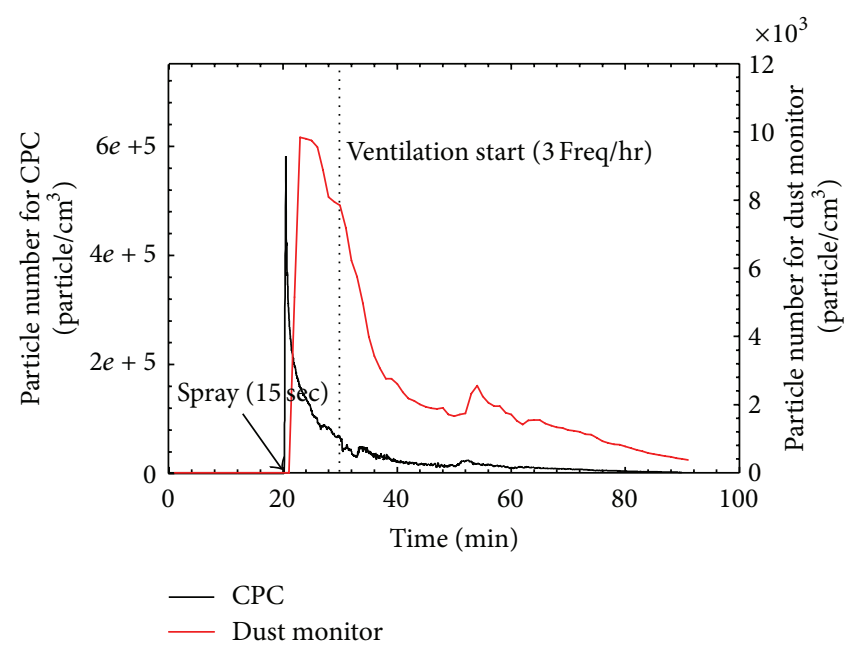

(a)

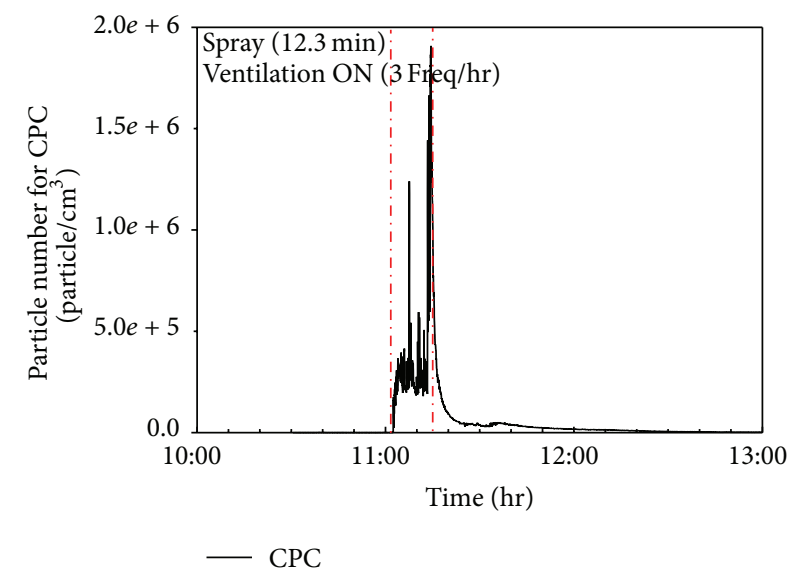

(c)

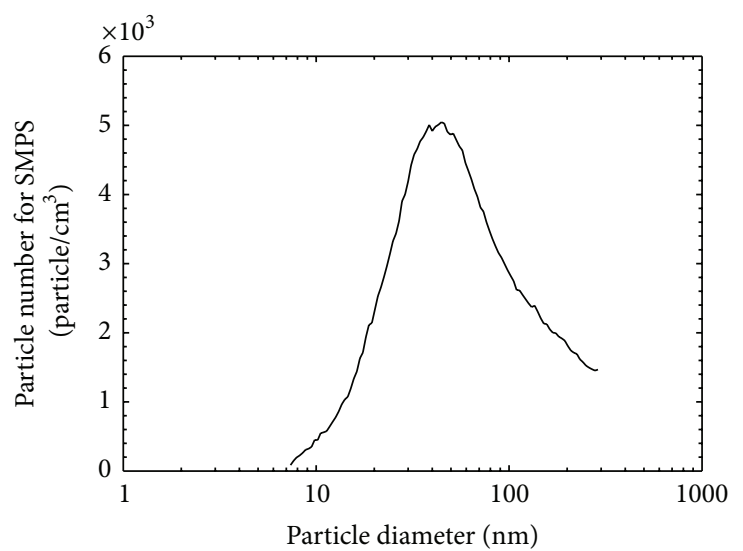

(b)

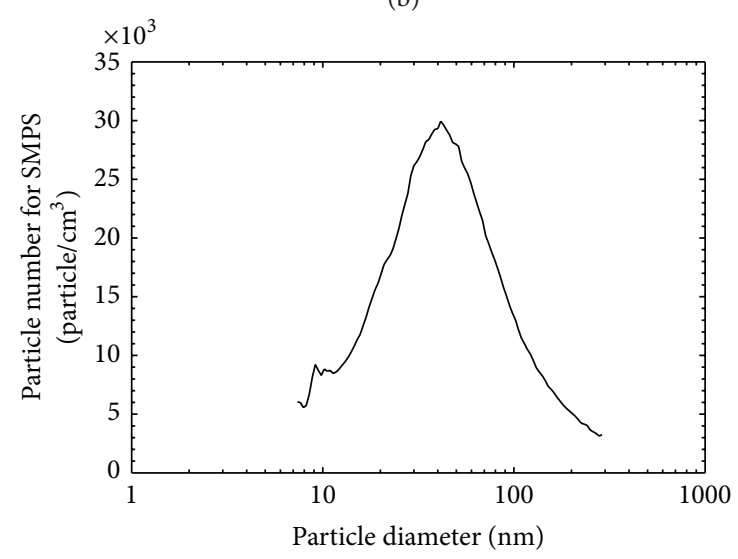

(d)

Figure 3: Particle number concentrations and particle size distribution. (a) Particle number concentrations for spray from Company A (15 sec spraying) measured using dust monitor and CPC, (b) particle size distribution for spray from Company B (15 sec spraying) measured using SMPS, (c) particle number concentration for spray (whole can, $10 \mathrm{~min}$ ) from Company B measured using dust monitor and CPC, and (d) particle size distribution for spray from Company B (whole can: 10 min spraying) measured using SMPS.

of exposure to nano-Ag and related Ag compounds from these products, along with aggregate exposure to nano-Ag from other products containing nano-Ag [4]. In addition, following the FIFRA Scientific Advisory Panel meeting in 2009, the US EPA announced a conditional registration for the pesticide product HeiQ Material Ag (HeiQ) containing nano-Ag as an active ingredient. In this case, the US EPA used a MOE approach and data including the product chemistry, environment fate and effects, human exposure, and toxicology to assess the risks of exposure to HeiQ [16]. 

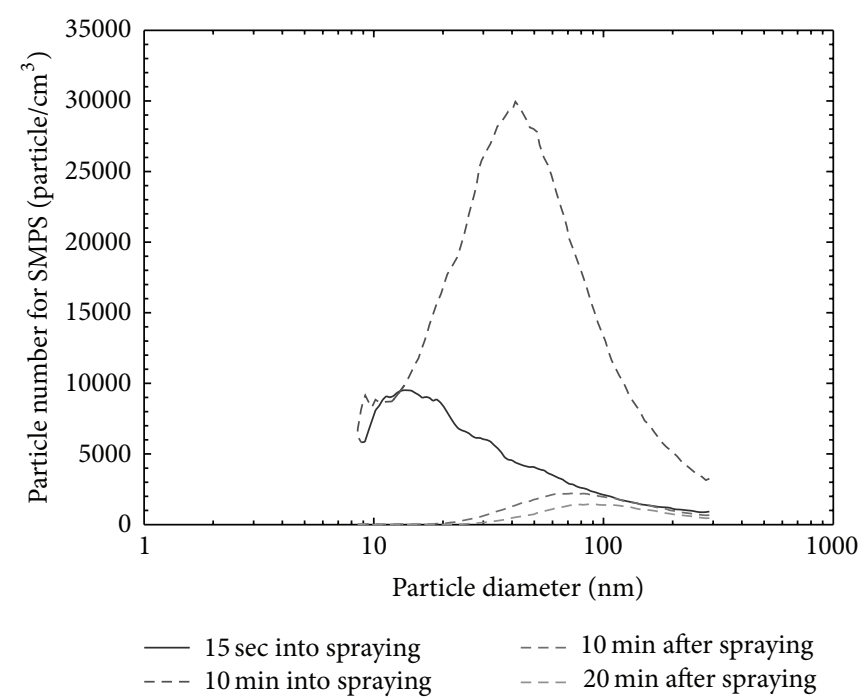

(a)

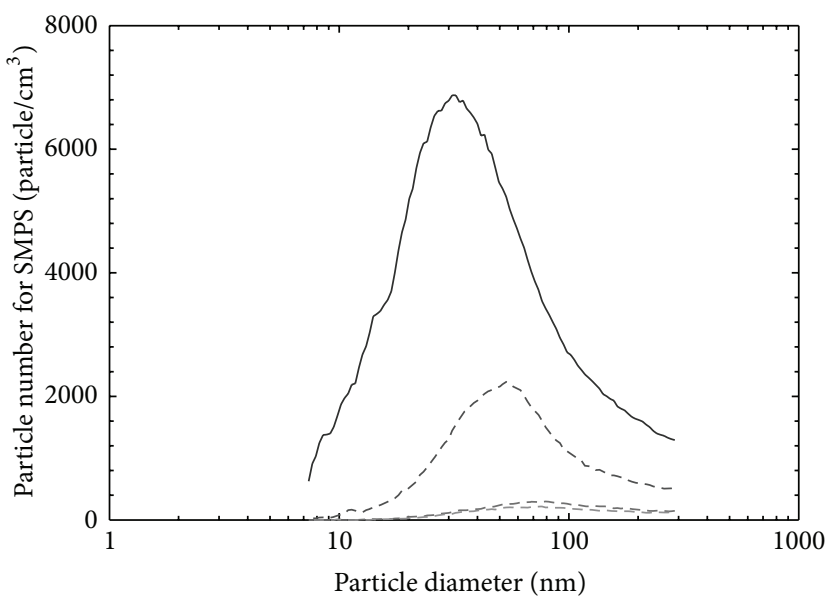

$\begin{array}{ll}-15 \mathrm{sec} \text { of spraying } & ---20 \mathrm{~min} \text { after spraying } \\ ---10 \mathrm{~min} \text { after spraying } & ---30 \mathrm{~min} \text { after spraying }\end{array}$

(b)

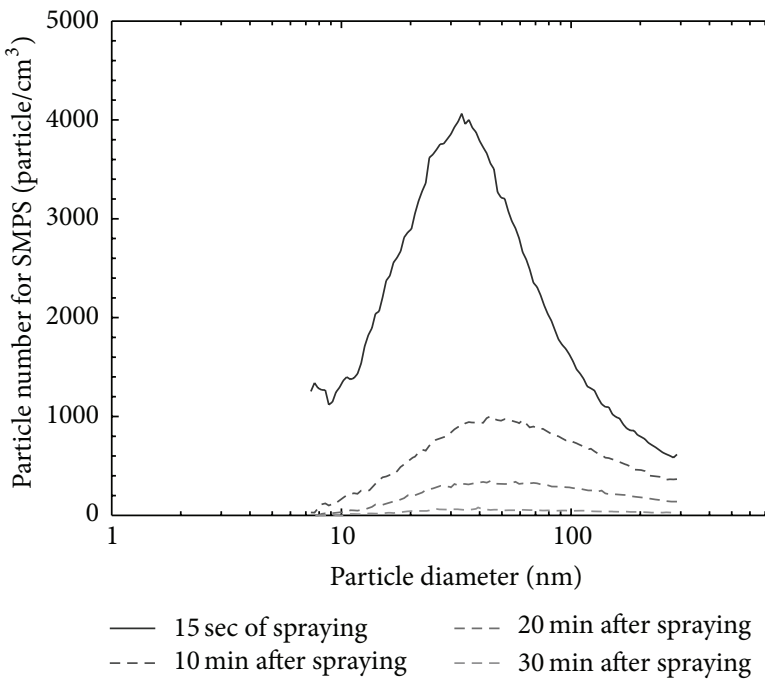

(c)

Figure 4: Differences in particle size distribution according to spraying time. (a) Particle size distribution for spray from Company B (10 min spraying) measured using SMPS, (b) particle size distribution for spray from Company B (15 sec spraying) measured using SMPS, and (c) particle size distribution for spray from Company A (15 sec spraying) measured using SMPS.

In this paper, a simulated AgNP exposure with a simulated chamber was set up because it is difficult to assess actual exposure condition when using antibacterial spray due to various condition application of use in duration, intensity, and frequency. Furthermore, unlike workers' exposure in workplace, such as attaching personal sampler to the breathing zone, exposure assessment on a consumer is not easy task due to difficulties in obtaining consent on exposure, arranging in exposure assessment, and requesting for actual use condition. Therefore, a simulated chamber was used to control the variables for exposure situation. The chamber study gave several advantages in estimating exposure leading to risk evaluation. It provides a proper condition for spray application, by allowing the assessment of AgNP concentration in terms of number and mass, and gives correct estimation of nanoparticle exposure avoiding contamination from other particles in ambient air condition. Using a simulated chamber platform, risk of AgNP consumer exposure in use of antibacterial spray can be appropriately evaluated. Additionally, risk evaluation using the MOE approach provided a valuable tool to estimate risk of exposure, improbable in real consumer exposure situation. The limitation of this chamber study could be overestimation of exposure when compared to real-life scenario, since the experiment provides higher frequency and intensity of exposure without circulating ambient air. It is an example that simulates worst-case scenario of exposure situation.

\section{Conclusion}

This paper used a MOE approach to assess the risk of consumer exposure to nano-Ag released from antibacterial 


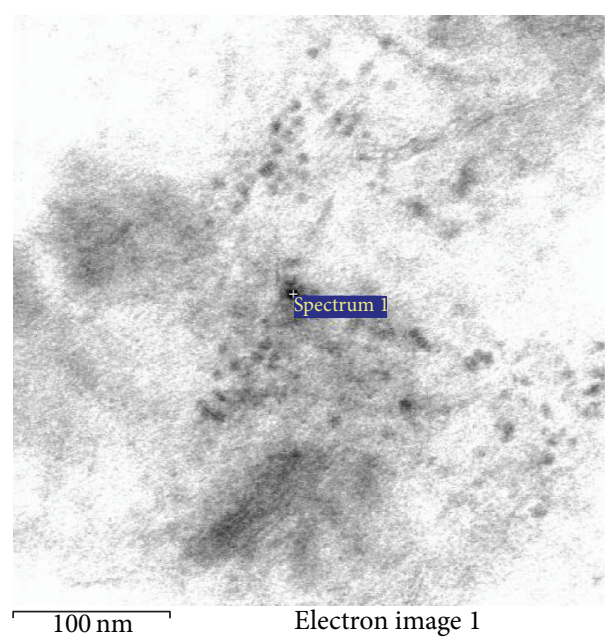

(a)

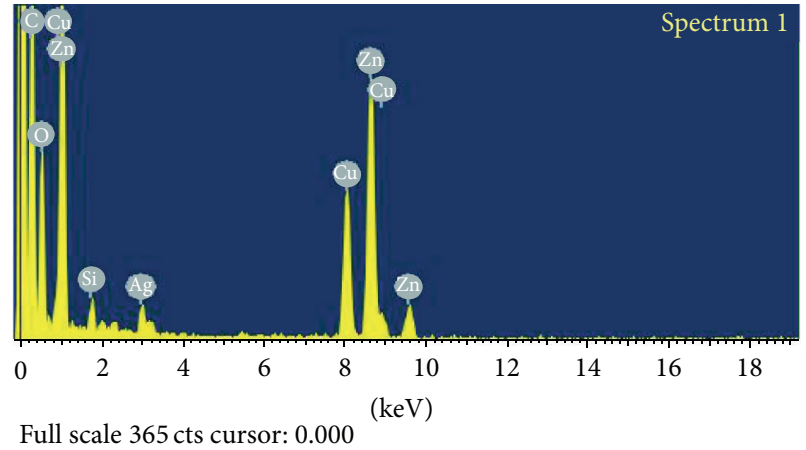

(b)

FIGURE 5: TEM-EDS of AgNPs released from spray.

sprays containing AgNPs. To estimate the inhalation and dermal exposure to AgNPs, the antibacterial sprays were used in a simulation chamber and the air concentration of AgNPs was measured in terms of the mass and number concentration, while the dermal exposure was estimated based on passive filter sampling. The results for all the products suggested an excessive risk of inhalation exposure for some of the tested sprays, as the MOE was lower than the no-risk concern level of 1000 . In contrast to the inhalation exposure, the dermal exposure results showed no-risk concern levels for the tested sprays. The current simulation setting and methods may be useful for estimating consumer exposure to nanomaterials.

\section{Disclaimer}

The authors alone are responsible for the content and writing of this paper.

\section{Conflict of Interests}

The authors report no conflict of interests.

\section{Acknowledgment}

This research was supported by the "Development of SafetyEvaluation-Based Technology for Nanoproducts to Promote Commercialization (10047829)" and "Development of Highly Usable Nanomaterial Inhalation Toxicity Testing System in Commerce (10052901)" through the Korea Evaluation Institute of Industrial Technology by the Korean Ministry of Trade, Industry \& Energy.

\section{References}

[1] ISO/TS 13830, Nanotechnologies-Guidance on Voluntary Labeling for Consumer Products Containing Manufactured Nano-Objects, International Organization for Standardization, Geneva, Switzerland, 2013.
[2] International Life Science Institute (ILSI), "NanoRelease Consumer Products," 2015, http://www.ilsi.org/ResearchFoundation/RSIA/Pages/NanoReleasel.aspx.

[3] Woodrow Wilson Center, "Project on emerging nanotechnologies," 2015, http://www.nanotechproject.org/cpi/.

[4] EPA, External Review Draft, Nanomaterial Case Study: Nanoscale Silver in Disinfectant Spray, EPA/600/R-10/081, EPA, Washington, DC, USA, 2010.

[5] J. H. Sung, J. H. Ji, J. D. Park et al., "Subchronic inhalation toxicity of silver nanoparticles," Toxicological Sciences, vol. 108, no. 2, pp. 452-461, 2009.

[6] KCL, "Nanoproduct-specific case studies and Safety evaluation," Tech. Rep., Korea Evaluation Institute of Industrial Technology, Seoul, Republic of Korea, 2014 (Korean).

[7] National Institute for Occupational Safety and Health (NIOSH), NIOSH Manual of Analytical Methods 7300. Elements by ICP (Nitric/Perchloric Acid Ashing), NIOSH, Cincinnati, Ohio, USA, 2003.

[8] National Institute for Occupational Safety and Health (NIOSH), NIOSH Manual of Analytical Methods 7402 Asbestos by TEM, National Institute for Occupational Safety and Health (NIOSH), Cincinnati, Ohio, USA, 1994.

[9] J. S. Kim, K. S. Song, J. H. Sung et al., "Genotoxicity, acute oral and dermal toxicity, eye and dermal irritation and corrosion and skin sensitisation evaluation of silver nanoparticles," Nanotoxicology, vol. 7, no. 5, pp. 953-960, 2013.

[10] F. F. Larese, F. D’Agostin, M. Crosera et al., "Human skin penetration of silver nanoparticles through intact and damaged skin," Toxicology, vol. 255, no. 1-2, pp. 33-37, 2009.

[11] EPA, Exposure Factors Handbook. Vol. I-III, Office of Research and Development, Environmental Protection Agency, Washington, DC, USA, 1997.

[12] EPA, PHED Surrogate Exposure Guide, Office of Pesticide Programs, EPA, Washington, DC, USA, 1998.

[13] T. M. Benn and P. Westerhoff, "Nanoparticle silver released into water from commercially available sock fabrics," Environmental Science and Technology, vol. 42, no. 11, pp. 4133-4139, 2008.

[14] T. Benn, B. Cavanagh, K. Hristovski, J. D. Posner, and P. Westerhoff, "The release of nanosilver from consumer products 
used in the home," Journal of Environmental Quality, vol. 39, no. 6, pp. 1875-1882, 2010.

[15] S. J. Froggett, S. F. Clancy, D. R. Boverhof, and R. A. Canady, "A review and perspective of existing research on the release of nanomaterials from solid nanocomposites," Particle and Fibre Toxicology, vol. 11, article 17, 2014.

[16] EPA, Proposed Decision Document for the Registration of HeiQ AGS-20 As a Material Preservative in Textiles, Office of Pesticide Program Antimicrobials Division, EPA, Washington, DC, USA, 2011. 

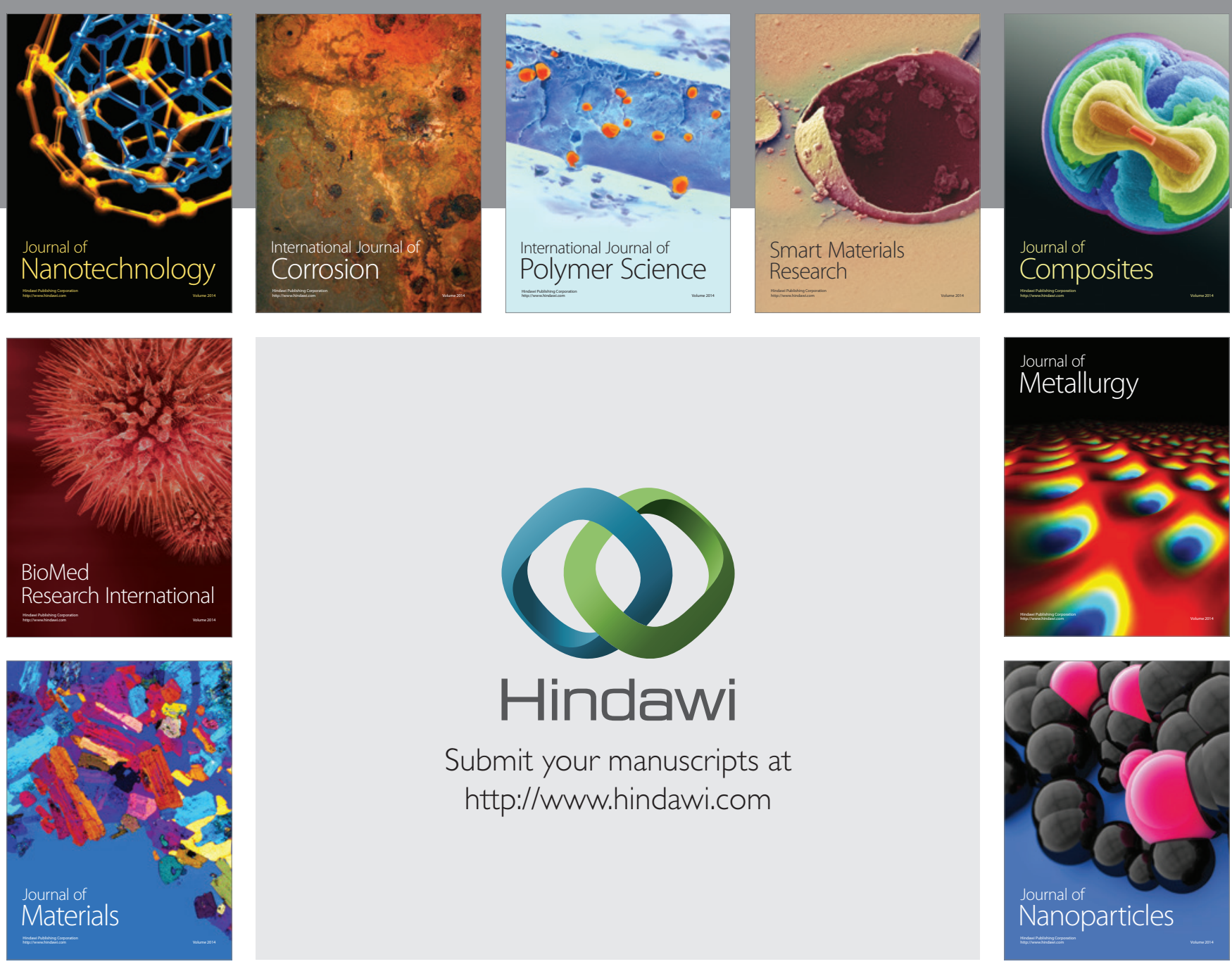

Submit your manuscripts at http://www.hindawi.com
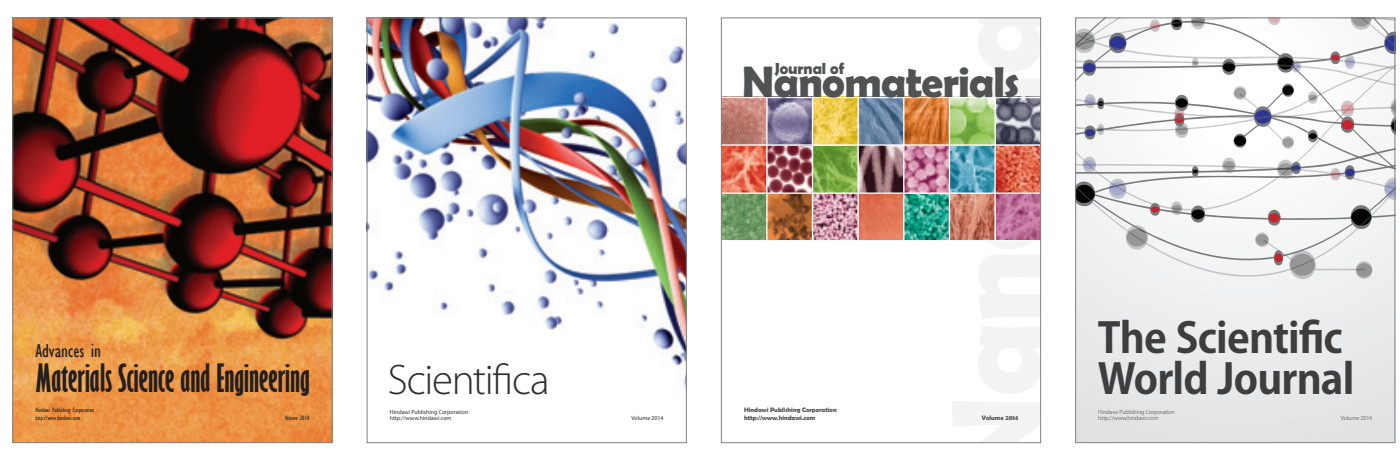

\section{The Scientific World Journal}
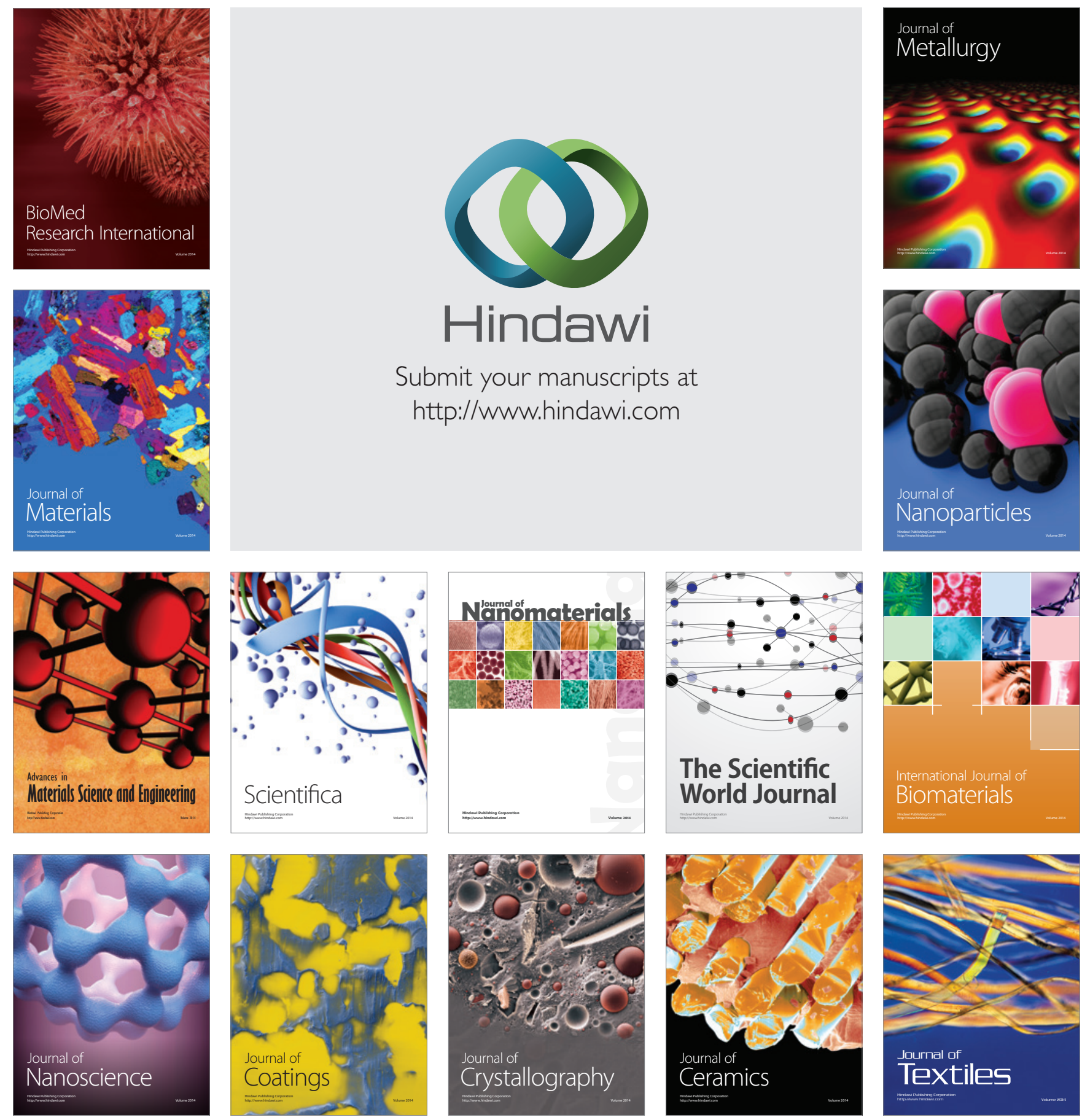